\title{
Comparison of Depression and Anxiety Levels in Patients between Behçet's Disease and Recurrent Aphtous Stomatitis.
}

\author{
Emre Aytuğar ${ }^{1}$, M.Ŏ̌uz Borahan², Filiz Namdar Pekiner ${ }^{2}$
}

\begin{abstract}
The aim of this study was to determine the existing relation between the Behçet's Disease (BD), Recurrent Aphthous Stomatitis (RAU) and psychological alterations of the patient, such as depression and anxiety. 30 patients with RAU, and 30 patients with BD, and 15 patients with healthy subjects were participated in the study. Systemic, dental and aphthous ulceration anamnesias of all the patients in the study group have been taken in detail and neckhead, oral mucosa and dental examinations have been made and data has been recorded. Spielberger State-Trait Anxiety Inventory and Beck Depression Inventory have been applied. It was observed that the depression level is higher in patient with $\mathrm{BD}$ and RAU in comparison with healthy subjects $(\mathrm{p}<0.05)$. Depression may play a role in manifestations of $\mathrm{BD}$ and RAU.
\end{abstract}

Keyworks: Behçet's Disease, psychological factors, RAU

\section{Introduction}

Behçet's disease (BD), first described by a Turkish physician, Hulusi Behçet, is a chronic, progressive disorder that affects many systems of the body, including the joints. It is a multisystemic disease with recurrent ulceration affecting both the oral and genital mucosa. Furthermore, patients with BD suffer from lesions affecting the eye, skin, joints and vascular systems $(1,2)$. BD is found worldwide, but there are marked geographical differences in disease expression. The incidence of BD cases per 100,000 population varies from 80-370 in Turkey to 13.5-20 in Saudi Arabia, Iran, Korea, Japan, China, and Oman $(1,2)$. Unlike BD, Recurrent Aphthous Ulcerations (RAU) is the most common oral mucosal disease.

\footnotetext{
${ }^{1}$ Department of Oral Diagnosis and Radiology, Faculty of Dentistry, University of Bezmi Alem Vakıf, Istanbul, Türkiye

2 Department of Oral Diagnosis and Radiology, Faculty of Dentistry, University of Marmara, Istanbul, Türkiye

Correspondence to:

Filiz Namdar Pekiner,

Marmara University, Faculty of Dentistry, Department of Oral Diagnosis and Radiology,

Guzelbahce Buyukciftlik Sok. No: 6, 34365 Nisantasi-Istanbul, Turkey.

Tel : + +90 (212) 2319120 ,

Fax : $\quad+90(212) 2465247$

E-mail : fpekiner@gmail.com
}

The reported prevalence in the general population varies from $5 \%$ to $66 \%$ with a mean of $20 \%(3,4)$. It is characterized by periodic painful, single or multiple ulcers that heal spontaneously $(4,5)$. Although the aetiopathogenesis of both $\mathrm{BD}$ and RAU have not yet been clarified, several mechanisims such as local trauma, nutritional deficiency, food hypersensitivity, genetics, infection, immunoglobulin, immune complexes and psychological stress have all been suggested as the causes of these diseases $(6,7)$. Previous studies have suggested that psychological disturbances such as stress and anxiety could play a role in the onset, BD and RAU (7-9). A chronic disease such as BD may lead to temporary or permanent functional disabilities and may cause some psychiatric disorders (7). Wells et al. (10) described the prevalence of psychiatric disorders in persons with or without chronic medical conditions. They found that there was a strong overall association between psychiatric disorders and medical conditions, and that persons with any recent chronic medical conditions had a high prevalence, relative to those without any chronic medical condition, of lifetime substance use disorders and recent mood and anxiety disorders (10). McCartan et al. (11) investigated the possible association between anxiety, as measured by Hospital Anxiety and Depression scale (HAD) in patients with RAU, concluding that stress may play a role in the aetiology of RAU. However, the obtained results were rather varied (7-9). Therefore, the aim of this study was to conduct a case-control investigation of influence of psychological stress on BD and RAU.

\section{Materials and Methods}

\section{Selection of the study group}

Thirty patients with BD and RAU, and 15 healthy subjects were participated in the study. Patients with BD were selected from the rheumatology out-patient clinics by expert rheumatologists, and consisted of 30 patients with BD fulfilling the International Study Group criteria (12). The diagnosis of RAU was made according the criteria of Lehner (13), and all were diagnosed as having minor or major RAU in the Department of Oral Diagnosis and Radiology, Faculty of Dentistry, Marmara University. Subjects with herpetiform ulceration or those in whom the diagnosis was not clear were excluded from the study. Fifteen healthy subjects composed of faculty personnel, participated after giving informed consent. At the time of venipuncture, none of the blood donors had been receiving 
any medication or had an overt infection. The BD and RAU patients were requested to sign a written informed consent statement. The study was carried out according to the recommendations of the Helsinki declaration and the study protocol was approved by the Local Committee of Research and Ethics of Marmara University. Systemic, dental and aphthous ulceration anamnesias of all the patients in the study group have been taken in detail and neck-head, oral mucosa and dental examinations have been made and data has been recorded. The level of anxiety and depression were analysed in BMS patients and controls by means of the Speilberger StateTrait Anxiety Inventory (SAI-TAI) and Beck Depression Inventory (BDI). State-Trait Anxiety Inventory (SAI-TAI) consist of two components. Both instruments are self-report rating measures of the affective, cognitive, and physiological manifestations of anxiety in terms of current experience (i.e.state anxiety) and long-standing patterns (i.e.trait anxiety). Trait anxiety was assessed using the trait component of the SAI-TAI. It has 20 items, each scored on a scale of 1 ('almost never') to 4 ('almost always'), which relate to how patients feel generally. Beck Depression Inventory (BDI) BDI is a 21 -item self-reported inventory. The items consist of symptoms of depression. Some items are related to physical concerns such as sleep disturbances and loss of weight. Other items refer to emotional (hopelessness, sorrow), motivational (willingness to work), and cognitive aspects (concentration, self-evaluation). For each symptom category, there are four sentences, and the subject chooses one according to his/her experience during the previous week. Each sentence is scored as $0,1,2$, or 3 . The sum of the points shows the level of depression. Test scores higher than 17 indicate a high level of depression. Turkish versions of these scales have been developed and thoroughly tested for reliability and validity in Turkey $(14,15)$.

\section{Statistical Analysis}

The data were analysed with NCSS (Number Cruncher Statistical System) 2007 and PASS 2008 Statistical Software (Utah, USA). The age and gender between patients with BD - RAU, and controls were analysed by means of the chi-squared test. BDI, SAI and TAI between patients BD and RAU, and healthy subjects were evaluated by Oneway ANOVA test. P values of less than 0.05 were interpreted as significant, and the level in confidence intervals was $95 \%$.

\section{Results}

\section{Characteristics of the study group}

Thirty patients (aged $17-64$ years, mean $37.03 \pm 13.84$ years, 12 men and 18 women) with RAU, 30 patients (aged 15-54 years, mean $38.06 \pm 8.55$ years, 15 men and 15 women) with BD and 15 healthy subjects (HS) (aged 23-51 years, mean 30.26 \pm 8.98 years, 9 men and 6 women) were studied. Statistical analysis revealed no difference according to age and gender between the groups ( $p>0.05)$ (Table 1).

Evaluation of BDI, SAI and TAI between patients BD and RAU, and healthy subjects

Although no statistically significant differences were observed in relation to SAI and TAI values between $\mathrm{BD}, \mathrm{RAU}$ and healthy subjects $(p>0.05)$, there were statistically significant differences in relation to BDI $(p<0.05)$. Subjects in healthy group had significantly lower mean values for BDI compared with patients BD ( $\mathrm{p}: 0.024 ; \mathrm{p}<0.05)$ and RAU (p:0.040; p<0.05). No statistically significant differences were observed in relation to BDI values between patients with BD and RAU ( $>0.05$ ) (Table 2)(Figure 1).
Table 1. Comparison of age and gender in patients with $\mathrm{BD}$ and RAU, and healthy subjects

\begin{tabular}{lccccc}
\hline & & BD & RAU & HS & p \\
& & $\mathbf{n}(\%)$ & n (\%) & n (\%) & (\%) \\
\hline \multirow{4}{*}{ AGE } & $15-24$ & $1(\% 3.3)$ & $7(\% 23.3)$ & $5(\% 33.3)$ & \\
& $25-34$ & $11(\% 36.7)$ & $7(\% 23.3)$ & $6(\% 40.0)$ & 0.073 \\
& $35-44$ & $10(\% 33.3)$ & $6(\% 20.0)$ & $3(\% 20.0)$ & \\
\multirow{4}{*}{ GENDER } & 45 & $8(\% 26.7)$ & $10(\% 33.3)$ & $1(\% 6.7)$ & \\
& Female & $15(\% 50.0)$ & $18(\% 60.0)$ & $6(\% 40.0)$ & \multirow{2}{*}{0.431} \\
& Male & $15(\% 50.0)$ & $12(\% 40.0)$ & $9(\% 60.0)$ &
\end{tabular}

Table 2. Evaluation of BDI, SAI and TAI between patients BD and RAU, and healthy subjects.

\begin{tabular}{ccccc}
\hline & $\begin{array}{c}\text { BD } \\
(\mathbf{n}=\mathbf{3 0}) \\
\text { mean } \pm \text { SD }\end{array}$ & $\begin{array}{c}\text { RAU } \\
(\mathbf{n}=\mathbf{3 0}) \\
\text { mean } \pm \text { SD }\end{array}$ & $\begin{array}{c}\text { HS } \\
(\mathbf{n}=\mathbf{1 5}) \\
\text { mean } \pm \text { SD }\end{array}$ & $\mathbf{p}$ \\
\hline BDI & $26.43 \pm 12.43$ & $25.76 \pm 10.39$ & $17.26 \pm 7.54$ & $0.022^{*}$ \\
SAI & $43.96 \pm 6.15$ & $44.10 \pm 5.89$ & $42.00 \pm 5.21$ & 0.489 \\
TAI & $43.53 \pm 7.91$ & $43.43 \pm 7.98$ & $42.20 \pm 8.36$ & 0.857 \\
\multicolumn{2}{l}{ Oneway ANOVA test } & $*$ &
\end{tabular}

BDI (Beck Depression Inventory), SAI (State Anxiety Inventory), TAI (Trait Anxiety Inventory)

Figure 1: BDI values in the patients with $\mathrm{BD}, \mathrm{RAU}$ and healthy subjects.

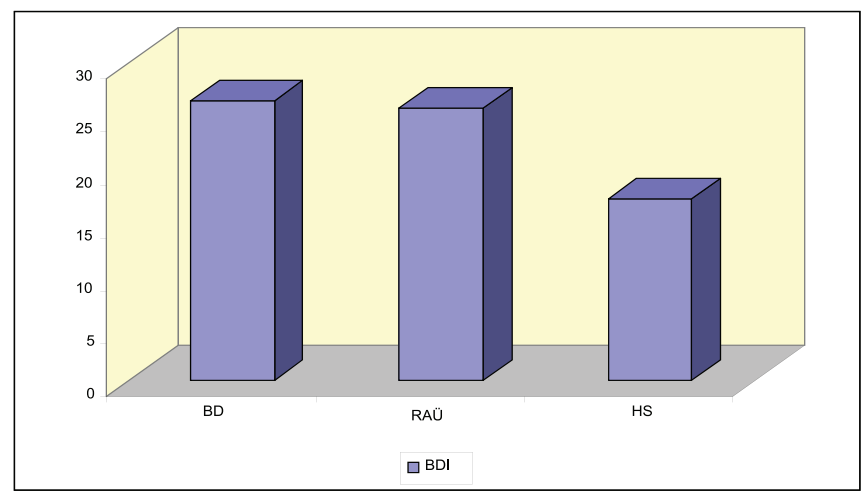

\section{Discussion}

Some reports in the literature indicate that $\mathrm{BD}$ and $\mathrm{RAU}$ may immunological, genetic, microbiological and psychiatric bases (7, 16). Anxiety and depression are seen frequently in patients with $\mathrm{BD}$. The real incidence of psychiatric symptoms in BD is unknown, but psychiatric symptoms in BD have been reported in $48 \%$ of the patients $(17,18)$. Gür et al.(7) thought that psychiatric symptoms can accompany BD because of its long-term clinical course and severe systemic complications. In their study, they observed that the depression and anxiety levels of the patients with BD were found to be high. However, it is difficult to assess whether this result is a primary finding of the disease itself or the consequence of long-term clinical progression and severe complications of $\mathrm{BD}$. In contrast to Sim (19) and Borson (20) BD is a psychiatric disorder. 
A variety of mechanisms may be considered as related between stres and recurrent oral ulcers. Paterson et al . (21) thought that an unknown biochemical reaction takes place or stress could possibly lead to atypical habits that injure the oral mucosa, such as bites in cheek and lips, leading to oral ulcer manifestation. AlbanidouFarmaki et al.(3) used for the evaluation of anxiety the Spielberger's STAI, a more sensitive method, which measures both trait anxiety as a general aspect of personality (STAI-T) and states anxiety as a response to a specific situation (STAI-S) and revealed a positive correlation between RAU and both state and trait anxiety; therefore it is not possible to distinguish the effect of the two components of anxiety separately, in their study. As a consequence, they cannot declare whether the RAU lesions are more related to state or trait anxiety. They determined that their study provides evidence for trait anxiety being a feature of some patients with RAU. Studies have been carried out trying to identify anxiety and depression levels in patients with RAU by means of diverse questionnaries such as the Hamilton Anxiety Depression, Hamilton Anxiety Scale and others. Despite contradictory results, psychological factors have been considered relevant to the pathogenesis of $\operatorname{RAU}(6,9,22)$. In our study, the depression values of the patients with $\mathrm{BD}$ and RAU were found to be found. Our results revealed that psychiatric symptoms in $\mathrm{BD}$ and RAU patients were more numerous than in the healthy subjects. However, it is difficult to assess whether this result is a primary finding of the disease itself or the consequence of long-term clinical progression and severe complications of BD and RAU. As the patients have higher values psychological symptoms are secondary to the disease, and these symptoms may manifest as a result of the inability to cope with the difficulties.

\section{Acknowledgements}

This article is presented at 17th Bass Congress, 3-6 of May 2012, in Tirana, Albania and this research was supported by the Marmara University Scientific Research Project Council [project no: SAGDKR-200407-0078].

\section{References:}

1. Sakane T, Takeno M, Suzuki N, Inaba G. Behçet's disease N Engl J Med 1999; 341:1284-1291.

2. El-Ageb EM, Al-Maini MH, Al-Shukaily AK, Al-Farsi Y, Richens ER. Clinical features of Behçet's disease in patients in the Sultanate of Oman; the significance of the antiphospholipid antibodies? Rheumatol Int 2002; 21:176-181.

3. Albanidou-Farmaki E, Poulopoulos AK, Epivatianos A, Farmakis K, Karamouzis M, Antoniades D. Increased anxiety level and high salivary and serum cortisol concentrations in patients with recurrent aphthous stomatitis. Tohoku J Exp Med 2008;214:291-296.

4. Ship JA. Recurrent aphthous stomatitis. An update. Oral Surg Oral Med Oral Pathol Oral Radiol Endod 1996;81:141-147.

5. Porter SR, Scully C, Pedersen A. Recurrent aphthous stomatitis. Crit Rev Oral Biol Med 1998;9:306-321.

6. de Barros Gallo C, Mimura MA, Sugaya NN. Psychological stres and recurrent aphthous stomatitis. Clinics 2009; 64:645-648.

7. Gür A, Saraç AJ, Burkan YK, Nas K, Çevik R.Arthopathy, quality of life, depression, and anxiety in Behçet's disease:relationship between arthritis and these factors.Clin Rheumatol 2006;25:524-531.

8. Mumcu G, Hayran O, Özalp DO, İnanç N, Yavuz S, Ergun T, et al. The assessment of oral health-related quality of life by factor analysis in patients with Behçet's disease and recurrent aphthous stomatitis. J Oral Pathol Med 2007; 36:147-152.

9. Soto-Araya M, Rojas Alcayaga G, Esguep A. Association between psychological disorders and the presence of oral lichen planus, burning mouth syndrome and recurrent aphthous stomatitis. Med Oral 2004; 9: 1-7.

10. Wells KB, Golding JM, Burnam M. Psychiatric disorder in a sample of the general population with and without chronic medical conditions. Am J Psychiatry 1988;145:976-981.

11. McCartan BE, Lamey PJ, Wallace AM. Salivary cortisol and anxiety in recurrent aphthous stomatitis. J Oral Pathol Med 1996;29:375-380.

12. International Study Group for Behçet's disease. Criteria for diagnosis of Behçet's disease. Lancet 1990; 335:1078-1080

13. Lehner T. Immunologic aspects of recurrent oral ulcers. Oral Surgery, Oral Medicine, and Oral Pathology 1972; 33: 80.

14. Hisli N. A study on the validity of Beck Depression Inventory. J Pyschol (Psikoloji Dergisi) 1983; 6:118-122.

15. Oner N, LeCompte A. Durumluluk-Sürekli Kaygı Envanteri El Kitabı. Boğaziçi Üniversitesi Yayınları,İstanbul, 1983.

16. Victoria JMN, Correia-Silva J, Pimenta FJ, Kalapothakis E, Gomez RS. Serotonin transporter gene polymorphism (5-HTTLPR) in patients with recurrent aphthous stomatitis. J Oral Pathol Med 2005; 34:494497.

17. Evereklioğlu C, Çokkeser Y, Doğanay S, Er H, Kızılay A. Audiovestibular evaluation in patients with Behçet's disease. J Laryngol Otol 2001;115:704-708.

18. Koptagel G, Tuncer O, Enbiyaoglu G, Bayramoğlu A psychosomatic investigation of Behçet's disease. Psychother Psychosom 1983; 40:263271.

19. Sim M. Behçet's syndrome as a psychiatric disorder. Am J Psychiatry $1983 ; 140: 816$

20. Borson S. Behçet's diseases a psychiatric disorder: a case report. Am J Psychiatry 1982; 139:1384-1349.

21. Paterson AJ, Lamb AB, Clifford TJ, Lamey PJ. Burning mouth syndrome: the relationship between the HAD scale and paratunctional habits. J Oral Pathol Med 1995; 24:289-292.

22. Chiappelli F, Cajulis OS. Psychobiologic views on stres-related oral ulcers.Quintessence Int 2004; 35:223-227. 